\title{
Successful Strategies for attracting more female students to Engineering Majors in Emerging Economies: The case of Southern Mexico
}

\section{Prof. Miguel X. Rodriguez-Paz, Tecnologico de Monterrey (ITESM)}

Prof. Rodríguez-Paz got his B.Sc. In Civil Engineering from Tecnologico de Oaxaca in 1993. He studied a M.Sc. In Structural Engineering at Tecnologico de Monterrey and got his Ph.D. from the University of Wales at Swansea in 2003 where he did research on Numerical Methods for Fluid Dynamics as a post-doc Research Officer. In August 2004 he joined Tecnologico de Monterrey at its Puebla Campus. He is a full professor of Applied Mechanics since 2009. His research topics include Engineering Education, Structural Dynamics and Applied Mechanics. He has been a member of the National System of Researchers (SNI) in the Mexican Council of Science and Technology. He has held several position within the School of Engineering, including Head of School and his current post as head of the department of Sustainable Technologies and Civil Engineering. He enjoys teaching Engineering in a fun way and likes to learn about Flipped Learning and Open Education. Since 2010 he is an Academic/educatational Youtuber.

\section{Prof. Israel Zamora-Hernandez, Tecnologico de Monterrey}

Israel Zamora-Hernández has a B.Sc. in Electronic Engineering from the Autonomous University of Puebla, Mexico. He has a M.Sc. in Digital Systems from Tecnologico de Monterrey. He has been a lecturer in the School of Engineering for over 18 years. His work especializes in attracting new students to STEM programs at University level. He has directed several teams in the Admissions Office at Tecnologico de Monterrey.

\section{Mr. Jorge A. Gonzalez, Tecnológico de Monterrey}

Master in Sciences with an speciality in Quality Systems and Industrial and Systems Engineer by ITESM in Mexico, twenty years of experience in engineering education, several projects in innovation of engineering education such as the use of 3D virtual ambiences as a way of developing competences.

\section{Dr. J. Asuncion Zarate-Garcia, Tecnologico de Monterrey (ITESM)}

J. Asuncion Zarate-Garcia received a B.S and a M. E. in Mechanical Engineering from Tecnologico de Monterrey and a Ph. D in Mechanical Engineering from Arizona State University.

$\mathrm{He}$ is currently Professor of Mechanical Engineering in the Mechatronics Department of the School of Engineering and Sciences of Tecnologico de Monterrey in Puebla, Mexico, where he teaches Heat Transfer, Thermodynamics and Fluid Mechanics. He also serves as the Director of Division of the School of Engineering and Sciences of Tecnologico de Monterrey in Puebla. His areas of interest are the analysis, design and optimization of thermal systems and the efficient and optimum use of energy in buildings. He has published some articles in the numerical simulation of single phase heated turbulent flow and two-phase turbulent boiling flow. 


\title{
Successful Strategies for attracting more female students to Engineering Majors in Emerging Economies: The case of Southern Mexico
}

\begin{abstract}
The attraction of new students to Engineering programs has always been a topic of interest for Universities all over the world. For the case of female students, in some countries the situation can be even more complicated as cultural issues might be involved.

In this work, we present the results of more than ten year of experience in the attraction of female students to Engineering programs such as Mechatronics Engineering, Industrial Engineering, Mechanical Engineering and Computer Science into a private University. The strategies presented in this paper are focused on the Southern Region of Mexico. This region presents the lowest index of human development according to United Nations results.
\end{abstract}

Different problems have been faced by the attraction team since the opening of our university campus in 2003, ranging from funding to the difficult cultural issues such as the case when an Engineering degree is not considered as a women's career choice in some regions of the country. The paper shows the trends in several Engineering programs with a positive increase in the number of girls pursuing an Engineering major.

Some of the best strategies are included along with the kind of activities that have worked best for attracting more women into Engineering . Also, recommendations on how to help them overcome peer and family pressure are described.

The conclusions and recommendations of this work can be used in other emerging economies that are working in increasing the number of women in STEM programs.

\section{Introduction}

In the past few years in our country the number of women in programs of Science and Engineering has been an object of study. The factors that affect the number of girls choosing a program of Science, Technology, Engineering and Maths (STEM) are many, from the cultural factors or family pressure to job opportunities once they have graduated from university. Many efforts from local and national governments have been put in place in countries like Mexico to encourage more women into careers that once were considered even by their own families, as men's careers. In this paper we interviewed a sample of two hundred women that are currently students or have studied at our university in two different campuses located in the South of Mexico so that we get information that could be applied to modify our attraction campaigns and events that take place in different cities. Southern Mexico shows the lowest ranking in the human development index (HDI) and the lowest numbers of women participating in higher education [1].

Our university is a multicampus university with twenty-six campuses across the country. The youngest campus was designed to serve as the main campus in Southern Mexico, giving service to students from 
this region of the country. It was opened in 2003 and since then, it has shown a steady growth in several programs. In the School of Engineering and Science, we have different programs:

- Automotive Design Engineering

- Biotechnology

- Civil Engineering

- Computer Science Engineering

- Industrial and Systems Engineering

- Mechanical Engineering with a minor in Management

- Mechatronics Engineering

In total, the number of students enrolled as per the Fall Term of 2019 is approximately 1400 with women being nearly a third of the population at $32 \%$. The purpose of this study is to know what women who have been students at our school as well as those currently enrolled have to say in order to improve the overall experience for new students and to increase the number of female students enrolled at our school. As in many other countries, the number of women in higher education and in our case, in STEM, can be an indicator of equal opportunities for women [2-4]. This work is the beginning of a project to improve the overall experience of our female students and to improve our attraction of talent processes so that more girls choose to study Engineering and Science in the most impoverished region of Mexico. It is important to mention that it is not only important to attract more women into STEM programs but to make sure that their experience once they are students is a good one since it has been shown that many girls face the most challenging time when they are already students not only in presence courses but also in new modalities that have been in place before as long distance learning [5-8] and that have become more relevant given the covid19 pandemic closure of campuses. Same problems might arise in a virtual classroom and those have to be addressed by the lecturers [9-11].

\section{Situation of our campus in the region}

As mentioned before, our university has several campuses (26) covering most regions of Mexico. We will focus the analysis on the main campus of the Southern Region, located in the city of Puebla, Mexico, which is the $4^{\text {th }}$ largest city in Mexico in terms of population with 1.576 million inhabitants according to the 2010 National Census. However, the city is known as being a city for students from the South of Mexico, with several private universities having campuses here and with one of the largest public universities in the country. Our university is a private university system, our campus has approximately 4,500 students.

The admission process is the same for all the country despite differences in the economic development of the regions of Mexico. The process begins with a high-school student enquiring about programs and scholarships to our admissions office. If the prospect has grades in highschool that are over seventy points out of hundred, she/he may continue with the admission process. Students with lower marks cannot aspire to be admitted to our university. 


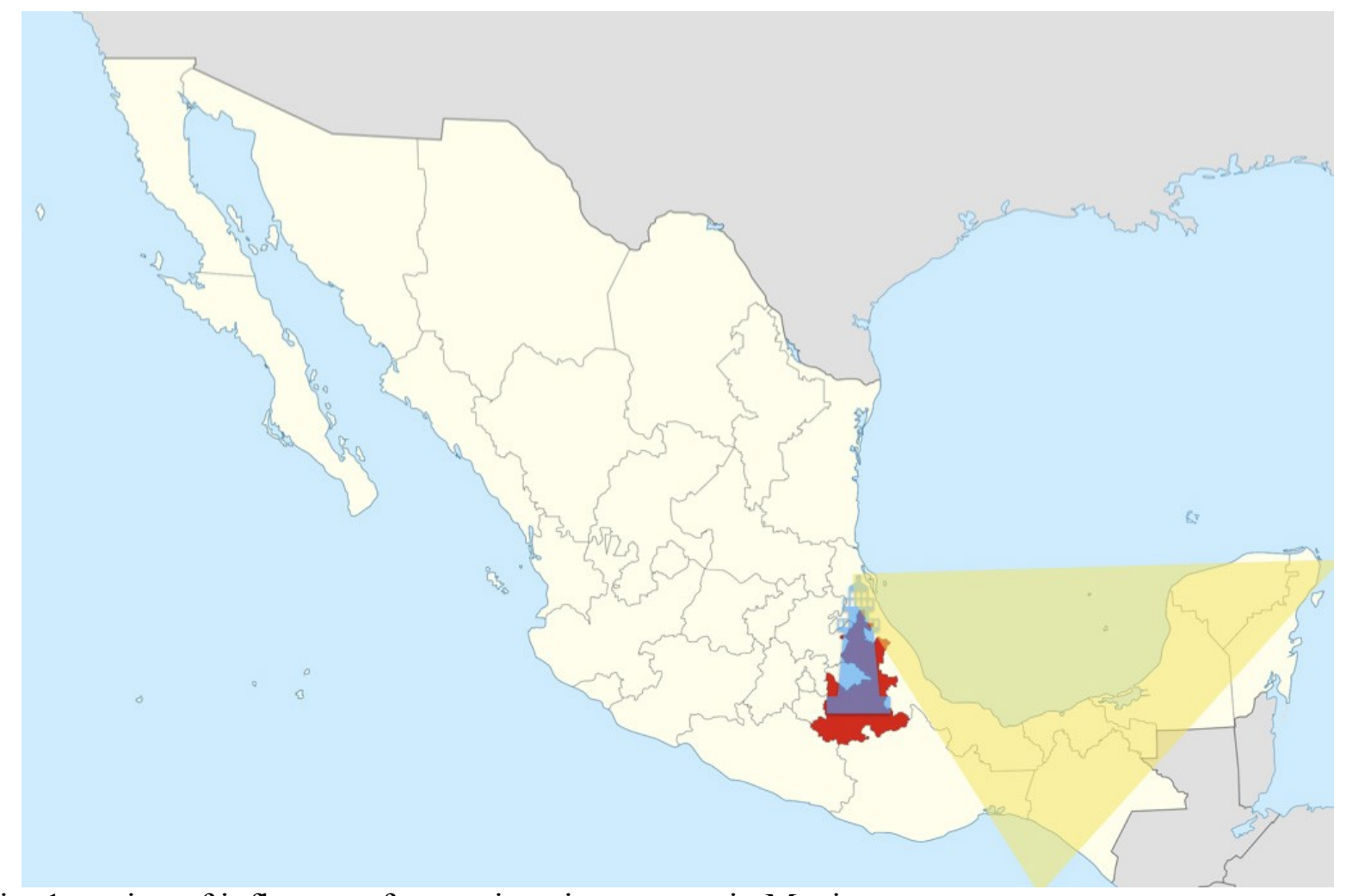

Fig. 1. region of influence of our university campus in Mexico.

Fig. 2 shows the admissions process from the first contact. As it can be seen, no distinction is made if the student is male or female. Once the prospect student fills an admission form she/he becomes an applicant and then an admission exam must be taken. In order to proceed to the next step, the applicant needs a minimum of 1180 points out of a maximum of 1600 points in the Standard College Board test. Once the exam is passed, the applicant becomes and admitted student and it is at this point that the student and her family start considering our university as their university. It could also be said that it is at this point that some girls start experiencing difficulties that male students might not face back home, especially if they are originally from a different city than our campus, as some families might not agree with the idea of her leaving to study in a different city. When the admitted student and family decide to continue with the process, a first payment is given to guarantee the next steps that end in the student receiving the timetable of the courses for the first semester. All this process takes months before the first day of term and during all this time, students and families might change their mind. Fig. 3 shows a Gantt chart of the admission process that starts in July the year before the first day of term in August the following year. At this current state of the process no distinction was made in the process for female or male applicants and we thought that we should include some steps to support girls and their families in this process. 

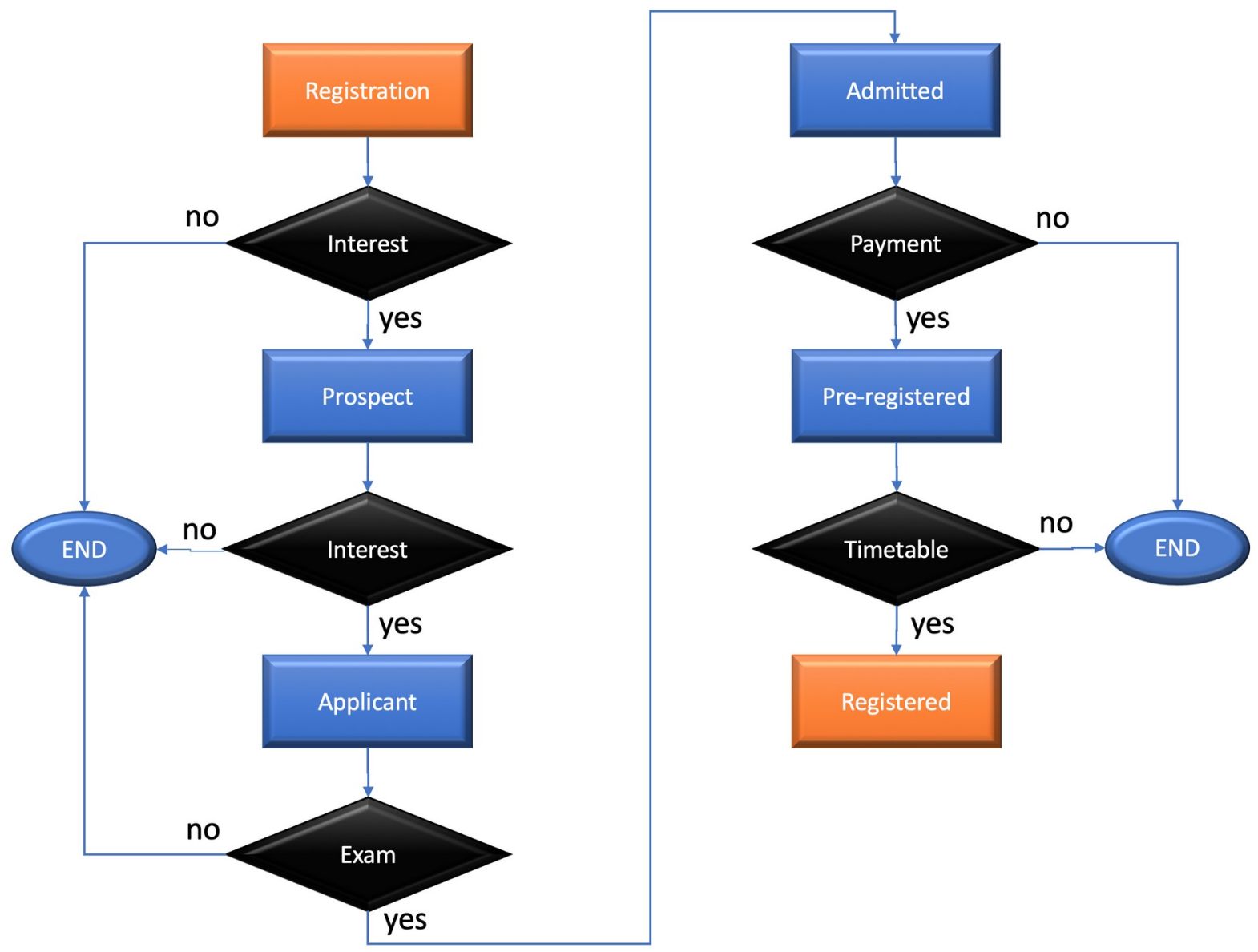

Fig. 2. Admission process for new students at our university (original process).

A modified process taking into account female applicants is shown in figure 4 with steps designed to develop a sense of belonging for girls and their families. The first step is to have a presence in all the events organized by our university for all admitted students, which it is the way it has been done always but now including a certain element for girls and their families alone. Another step is a talk with a female professor or lecturer from the School of Engineering and Science that can be arranged for the family or the applicant. In this kind of meetings the professor can talk about the career that girls can pursue after graduation and even talk about their own experience. Another type of event that we have organized includes round tables with leading female engineers of the region and some female alumni of our university that have already taken off in their careers. We have noticed that this type of events is very encouraging for younger female engineering students and some future students that are somehow in the initial stages of the admission process. 


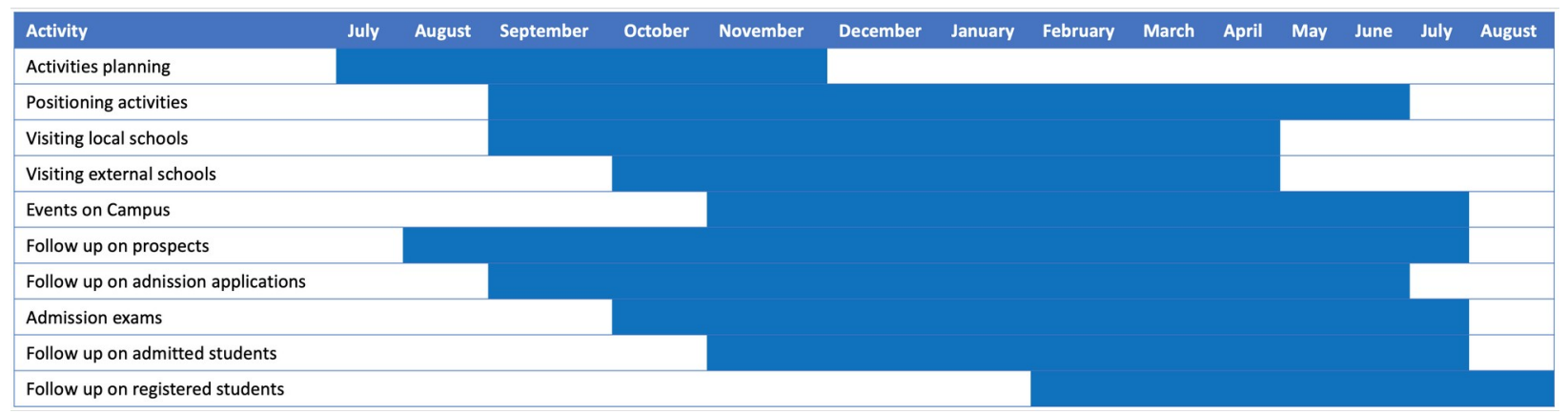

Fig. 3. Gantt graph of the admission process.

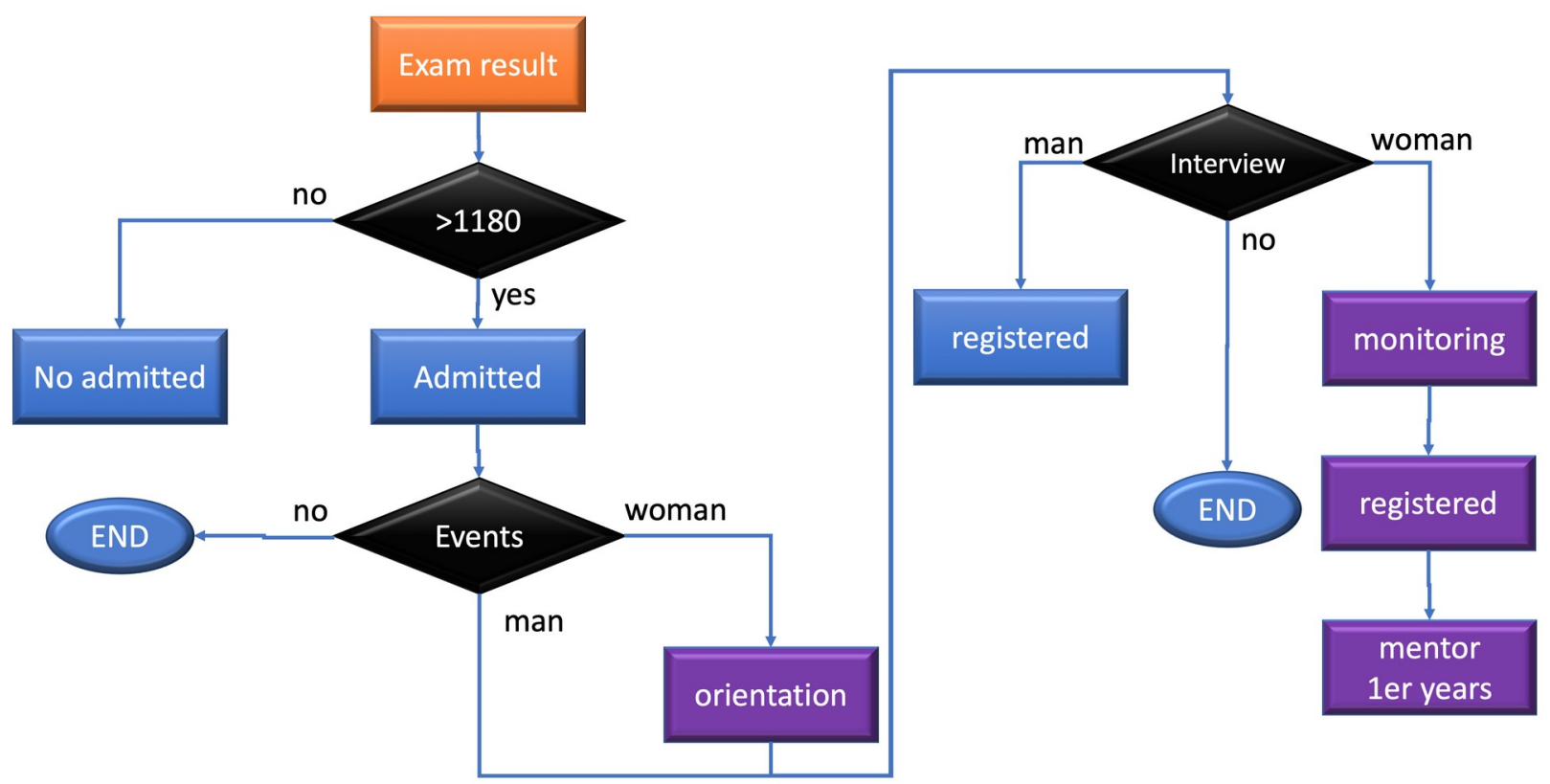

Fig. 4. Modified admission process to take into account female applicants

\section{Students and alumni perception about being Female Engineering Students}

A questionnaire was designed and applied to 200 female students and alumni from our university, the questionnaire was uploaded to Google forms and sent to all respondents using Whatsapp chat. The questions are about the admission process, the reaction from their families from the first moment they decided to study an Engineering program, their first year experience in the university and some suggestions they wanted to give to the university to improve the overall experience of female applicants and students. With the answers to the survey, some graphs were made and wil be shown next.

The first question was "When you decided to study Engineering, your family a) agreed with the decision, b) disagreed with the decision". Fig. 5 shows the results to this question and as we can 
see not $100 \%$ of students were supported in the decision, with $7 \%$ of students answering that their families did not agree with their choice of career.

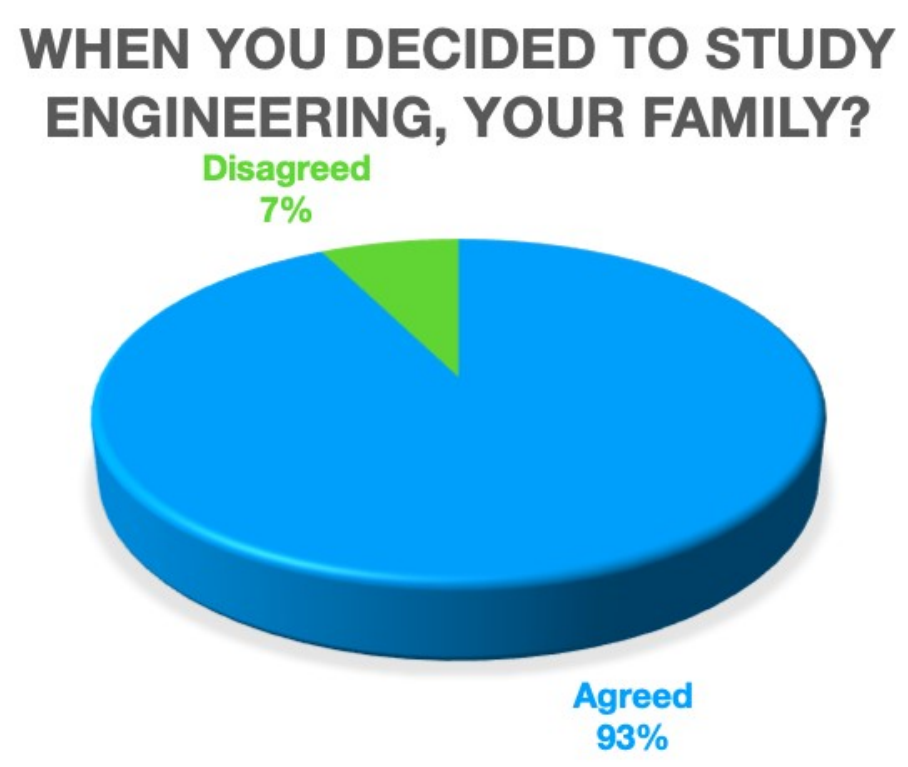

Fig. 5. Answer to question 1: "Your family agreed or disagreed when you decided to study Engineering".

Second question was about the perception of the respondents on whether they still consider that there are taboos for women who choose Engineering as a career. Three options were given as possible answers: a) yes, b) no and c) maybe. Fig. 6 shows the results of this question with an striking 63\% answering that yes, they believe there are still taboos here in Southern Mexico for women who choose an Engineering program. Another important percentage, 24\% are not sure and only $13 \%$ think that there are not taboos for women choosing Engineering.

Third question was about the decisive factor for the applicants to study Engineering. Fig. 7 shows the results, with $48 \%$ mentioning work-place opportunities, $35 \%$ the university as the decisive factor with all that it offers to their students, $13 \%$ mention family tradition or engineers in the family and 4\% replied that it had to do with friends already studying Engineering. Fig. 6 Answer to the question on taboos for women choosing Engineering.

Fourth question was related to the choice of the university, with three main options given as answer: a) Academic level of university, b) Programs available at the university, c) College prestige or fame. Results indicate that the most mentioned option was the academic level with $52 \%$ with college fame at $30 \%$ and the availability of programs on campus at $18 \%$. Fig. 8 shows these results. 


\section{DO YOU CONSIDER THERE ARE STILL TABOOS FOR WOMEN TO STUDY ENGINEERING ?}

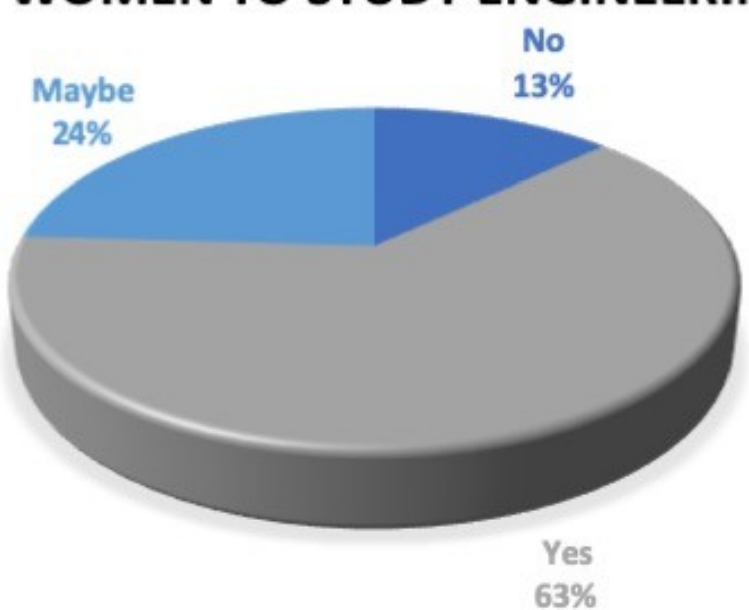

Fig. 6. Are women still facing taboos when choosing Engineering?

\section{WHICH FACTOR CAN BE CONSIDERED AS DECISIVE FOR YOU TO START STUDYING ENGINEERING?}

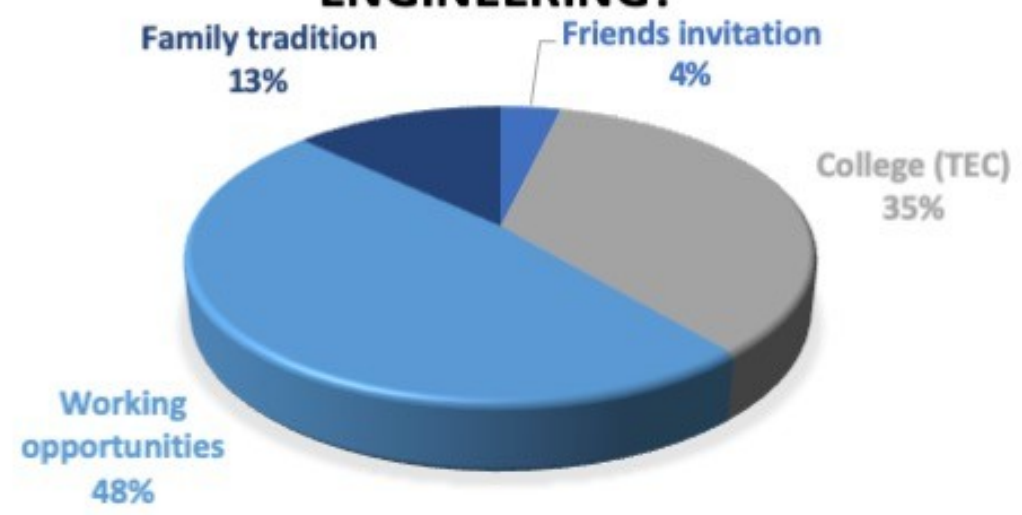

Fig. 7. Decisive factor for girls selecting Engineering for college degree. 


\section{WHY DID YOU JOIN TEC TO STUDY ENGINEERING?}

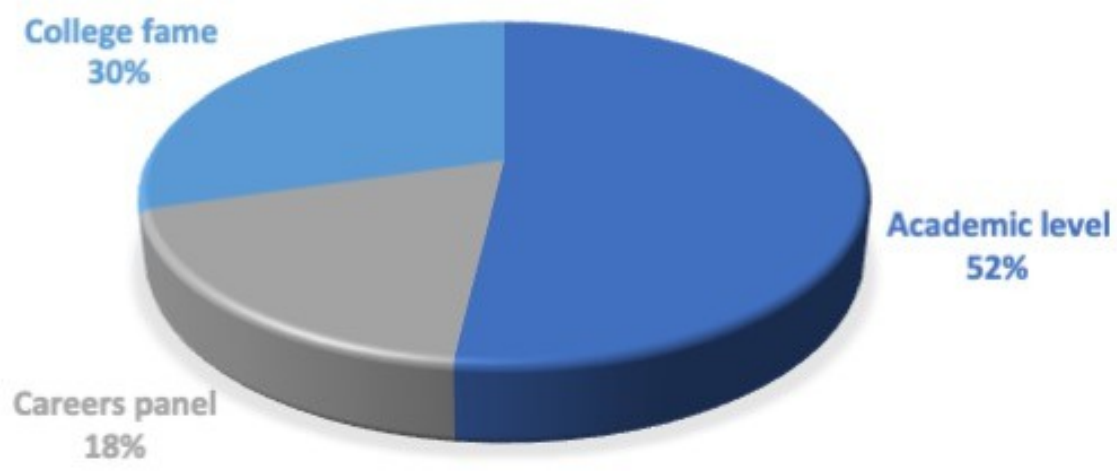

Fig. 8. Factors taken into account when deciding the choice of university.

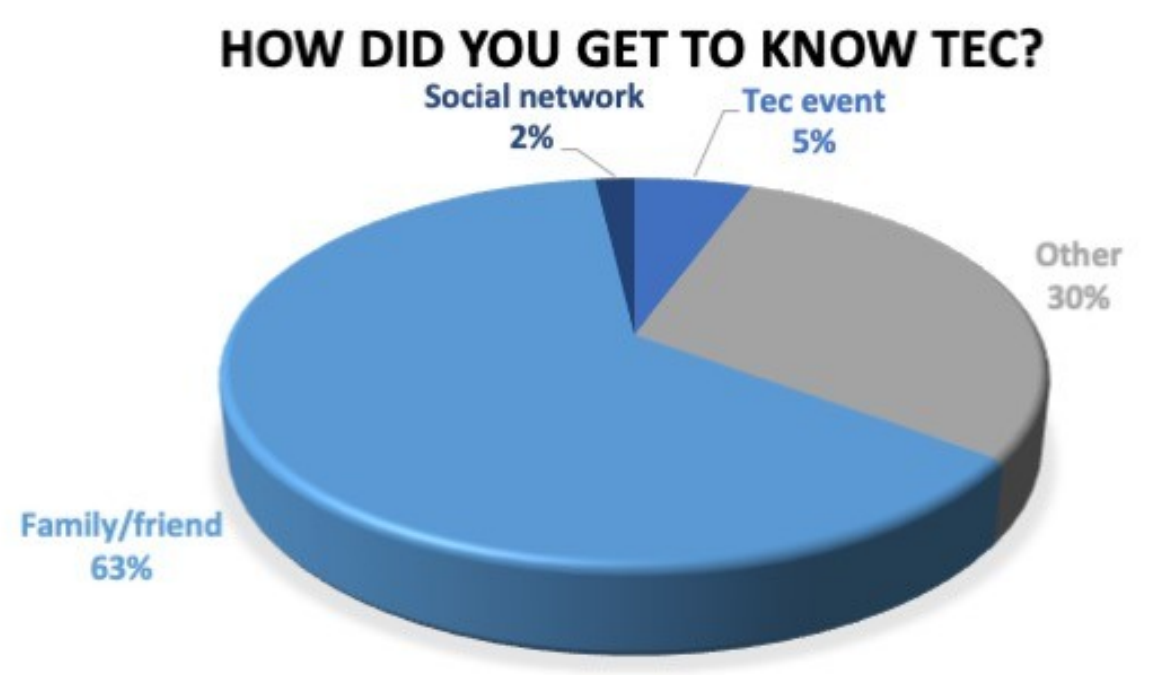

Fig. 9. How female applicants got to know our university. 
Another question, number five, was the reason they got to know the university before deciding to apply for admission. Fig. 9 shows the results in which we can see the influence of family and friends, as $63 \%$ indicate that they knew the university trough family members or friends. University events like open days or visit to their high schools is at $5 \%$ and $2 \%$ said that through social networks. $30 \%$ of answers were classified as other reasons.

\section{WHAT WAS YOUR EXPERIENCE IN YOUR FIRST STUDYING YEAR?}

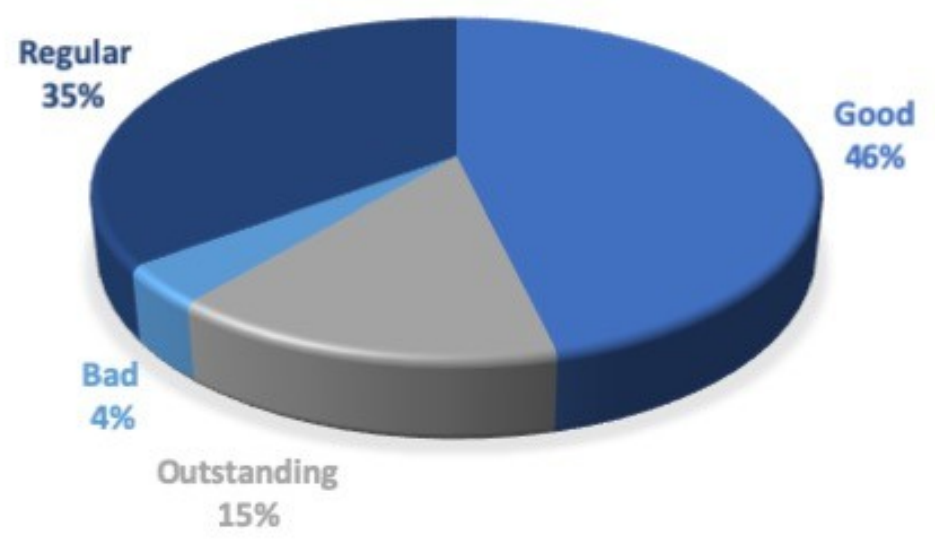

Fig. 10. Overall experience as first year female students

The next set of questions had to do with their experience as students once they were already in the university. The very first question of this type had to do with how they considered their firstyear experience in the School of Engineering as female students. Fig. 10 shows the results of this question: $15 \%$ considered their experience as "outstanding", $46 \%$ considered the experience as "good", $35 \%$ as "regular" but $4 \%$ considered it as a "bad" experience.

The following question of this subset was "do you consider that there should be a follow up program focusing on female students in the first year?". Nearly $90 \%$ of girls consider that we are not doing enough and that a special tutoring program for girls in their first year of and Engineering program should be included. Only $11 \%$ of girls consider that it is not necessary.

Asking more about what we could do as university to increase the interest of more girls into Engineering, from their own experience, they answer as shown in Fig. 12. The majority (52\%) think that talking about successful women's stories in Engineering will help to attract more young women into this field. $44 \%$ think that breaking taboos is needed and $4 \%$ consider that there should be work done in changing the regional culture in Southern Mexico. 


\section{DO YOU CONSIDER THERE SHOULD BE A FOLLOW UP PROGRAM FOCUSING ON FEMALE STUDENTS IN THE FIRST YEAR?}

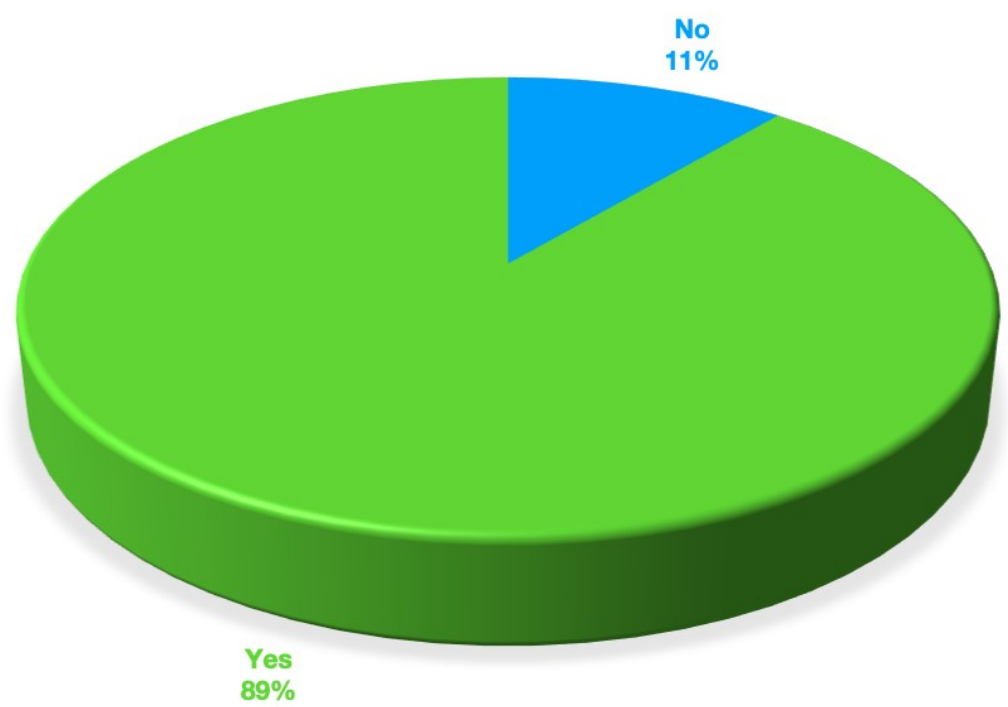

Fig. 11. Answers to the questions if there should be a special program for women in first year of Engineering school.

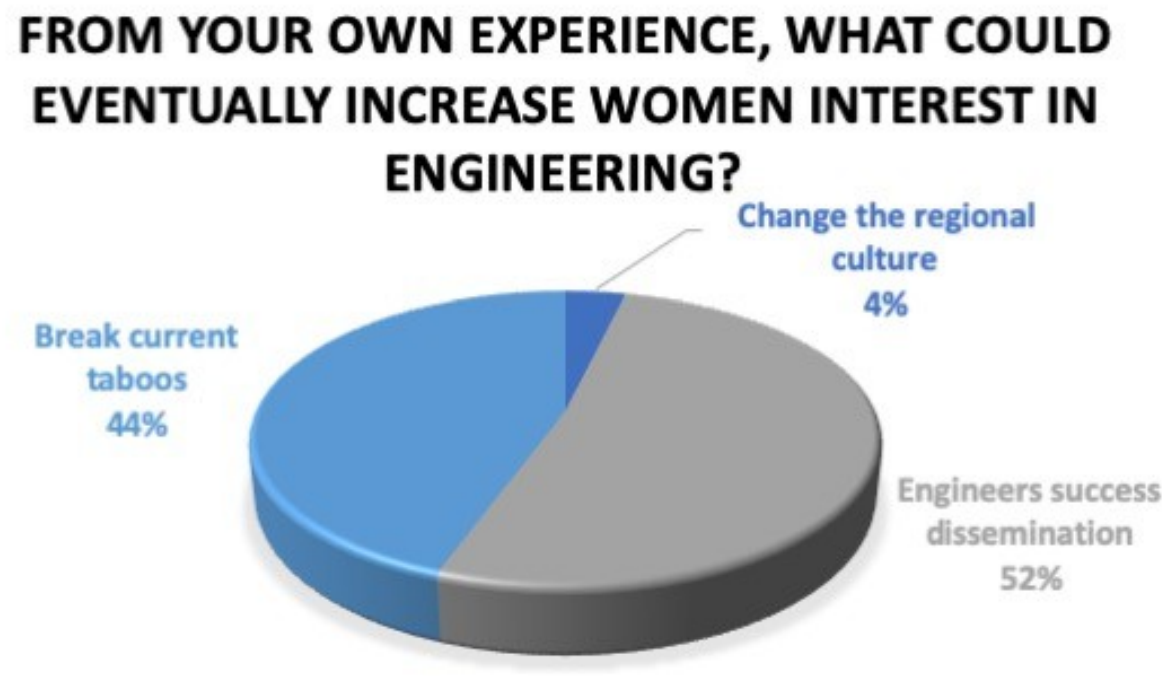

Fig. 12. Opinion of alumni and students on what can be done to increase interest of girls in Engineering. 


\section{IN WHICH SECTOR WILL YOU WORK PROFESSIONALLY?}

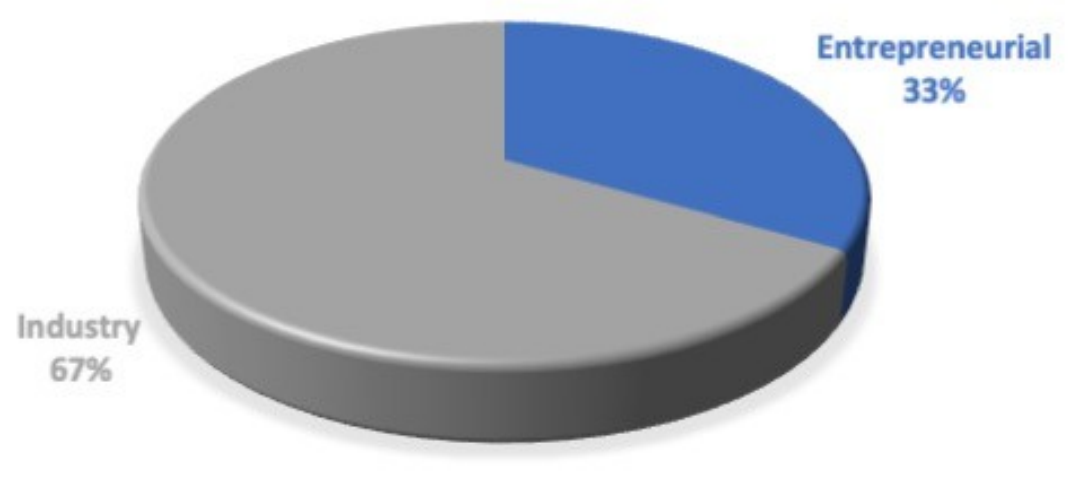

Fig. 13. Preferred sector for careers for young female engineers.

In our educational model we also encourage students to develop an entrepreneurial spirit and it is part of our vision as Institution. Last question was about how the current students and even alumni see themselves in the future: a) working for industry or b) as entrepreneurs . Fig. 13 shows the answers to the question with two-thirds answering that they want to work in industry related jobs, whereas one third would like to have their own business.

\section{Analysis and proposals to attract more women into Engineering in Mexico}

As we have seen in the answers given by female students and alumni, something can always be improved. Some things can be dealt within the university and others are part of the local culture and might take longer to change. As from our side, the university can adapt its admission process and once the girls are part of the School of Engineering, introduce programs to give a follow-up at least for the first year of studies. Another important factor that has to be considered is the family of the girl that has decided to study an Engineering program. In some cases the decision implies that the girl has to move to a different city, most probably larger than their own city as Puebla is the largest city in Southern Mexico. Some elements of the process have to include the participation of the family in talks, visits or even interviews with faculty members (female ones) so that any fears that the family had at first vanish and they feel accompanied by the institution. In summary we suggest that the following list of events are included in any admission process for a university in a region like Southern Mexico, where cultural factors still affect the decision of younger women when deciding for a career: 
- Include interviews with female members of faculty working in the Department with most courses for the program that the female student is studying. For instance, if the prospectus girl decides to study Industrial and Systems Engineering, find a date in which she is received on campus by the lecturer/professor and give her some time to ask questions and clear up any doubts she may have about the program or the School. We have found that his step has helped a lot undecided applicants.

- In events that take place in other cities, have a table or information desk with female members of staff from our university. If possible, a female lecturer could make the trip to give the talk to families and admitted applicants.

- Organize special events such as round tables with successful female Engineers. If possible, invite female alumni from our own university. This has worked pretty well in motivating not only prospectus students but current students as well.

- Encourage the opening of chapters for different Professional Societies or Associations that already have events prepared for female engineering students. Professional Societies such as the American Society of Mechanical Engineers or the American Society of Civil Engineers. Currently in our campus we already have a local society called "Women in Engineering" with the participation of Faculty Members.

- Follow-up each individual case if possible. In the results of our survey, a hight percentage suggested we should have an established program to give follow up to all girls within their first year in the Engineering School. Female Faculty Members could be very good allies for this purpose and it could include social events or informal meetings.

- Always review what can be improved in terms of attention to women in the Engineering School.

\section{Conclusions}

We have presented in this work the perception of current Engineering students as well as the perception of Engineering alumni that studied in our university campus as young female students. The answers given to the survey applied to this group of women show that there is still a lot of work to be done in order to make girls feel welcomed during their studies and when they are deciding on which program to study. Many girls still face criticism even by family members when they communicate the idea that they want to pursue a career in Engineering. Local culture in Southern Mexico is still very conservative and some families find it difficult to let their young daughters travel to a bigger city such as Puebla, Mexico to study their college degree. We started this study with the main objective of knowing the current state in our own university, where only $32 \%$ of students are female. As we want to increase this number, we decided to interview current students and women who graduated from our university as Engineers. Many practices that we have been doing in an informal manner should be incorporated into a formal process of following up on each individual case of female students during at least, their first year in college. Other events like seminars and talks in different locations in our region could also help in changing the local culture and removing what our respondents considered as "taboos". As it has already been indicated in other studies, it is important to accompany female students once they are part of any Engineering School as bullying still exists from male students and in rare cases, even from some teachers. This project is a continuous improvement work and in future publications, results will be shown on the improvement of numbers of women in each 
Engineering program and the overall improvement of their perception. The analysis and conclusions shown in this work can be applied to other regions of the world where similar cultural and economic conditions exist, as women still face many problems not only inside an Engineering faculty but sometimes even at home when they decide for an Engineering career.

Acknowledgment

Authors would like to acknowledge Writing Labs, TecLabs, Tecnologico de Monterrey, for the Financial Support provided to this project. Special thanks to Mrs Claire Teste de Sagey for the support given to this project.

\section{References}

[1] United Nations Development Programme, Human Development Reports, Country Profile: Mexico, retrieved from http://hdr.undp.org/en/countries/profiles/MEX

[2] Keune, Anna, Peppler, Kylie A. and Wohlwend, Karen E. "Recognition in makerspaces: Supporting opportunities for women to "make" a STEM career", Computers in Human Behavior, Volume 99, 2019, Pages 368-380, ISSN 0747-5632, https://doi.org/10.1016/j.chb.2019.05.013.

[3] Sassler, Sharon, Glass, Jennifer, Levitte, Yael and Michelmore, Katherine M. "The missing women in STEM? Assessing gender differentials in the factors associated with transition to first jobs", Social Science Research, Volume 63, 2017, Pages 192-208, ISSN 0049-089X, https://doi.org/10.1016/j.ssresearch.2016.09.014.

[4] Pietri, Evava S., Drawbaugh, Montana L., Lewis, Arielle N. and Johnson, India R. "Who encourages Latina women to feel a sense of identity-safety in STEM environments?", Journal of Experimental Social Psychology, Volume 84, 2019, 103827, ISSN 0022-1031, https://doi.org/10.1016/j.jesp.2019.103827.

[5] Fischer, Stefanie. "The downside of good peers: How classroom composition differentially affects men's and women's STEM persistence”, Labour Economics, Volume 46, 2017, Pages 211226, ISSN 0927-5371, https://doi.org/10.1016/j.labeco.2017.02.003

[6] Rodríguez-Paz, Miguel X., Gonzalez-Mendivil, Jorge A., Zarate-Garcia, J. Asuncion and Peña-Ortega, Luis O., "The Positive Effects of Using Social Networks in Courses of Applied Mechanics on Students' Performance”, Proceedings of the ASME 2018 International Mechanical Engineering Congress and Exposition (IMECE), ASME (2018).

https://doi.org/10.1115/IMECE2018-87217 
[7] Rodríguez-Paz, Miguel X., Gonzalez-Mendivil, Jorge A., Rojas, Juan-Carlos and Núñez, Martha Elena. "Use of an offline video repository as a tool to improve students' perfomance in Engineering courses versus real-time long distance courses", Proceedings of the 2019 IEEE Global Engineering Education Conference (EDUCON), (2019), pp. 574-581. https://doi.org/10.1109/EDUCON.2019.8725105

[8] Escherle, Nora A., Ramirez-Ramirez, Silvia I. , Basawapatna, Ashok R. , Assaf, Dorit, Repenning, Alexander, Maiello, Carmine, Endo, Yasko Ch. and Nolazco-Flores, Juan A. "Piloting Computer Science Education Week in Mexico". Proceedings of the 47th ACM Technical Symposium on Computing Science Education (SIGCSE '16). Association for Computing Machinery, New York, NY, USA, (2016), pp. 431-436.

https://doi.org/10.1145/2839509.2844598

[9] Danbold, Felix and Huo,Yuen J. "Men's defense of their prototypicality undermines the success of women in STEM initiatives", Journal of Experimental Social Psychology, Volume 72, 2017, Pages 57-66, ISSN 0022-1031, https://doi.org/10.1016/j.jesp.2016.12.014

[10] Griffith, Amanda L. "Persistence of women and minorities in STEM field majors: Is it the school that matters?", Economics of Education Review, Volume 29, Issue 6, 2010, Pages 911922, ISSN 0272-7757, https://doi.org/10.1016/j.econedurev.2010.06.010

[11] Robnett, Rachael D. and Thoman, Sarah E. "STEM success expectancies and achievement among women in STEM majors", Journal of Applied Developmental Psychology, Volume 52, 2017, Pages 91-100, ISSN 0193-3973, https://doi.org/10.1016/j.appdev.2017.07.003 